\title{
LA LIBERTAD DE ASOCIACIÓN EN EL CONSTITUCIONALISMO DE AMÉRICA LATINA
}

\author{
MIGUEL CARBONELL ${ }^{*}$
}

\begin{abstract}
RESUMO: O artigo realiza análise de direito comparado da proteção da liberdade de associação nos países da América Latina, tendo em vista a característica interna das associações e a eficácia entre particulares do direito de associação. Em seguida, examina os precedentes da Corte Interamericana de Direitos Humanos sobre direito de associação, concluindo que estes apesar de poucos, constituem norte significativo para a proteção do direito de associação no continente, onde o verdadeiro problema é a efetivação da proteção do direito e não sua consagração constitucional.
\end{abstract}

PALAVRAS-CHAVE: Direito de Associação; América Latina; Direitos Fundamentais; Eficácia Horizontal.

ABSTRACT: The article endeavors the compared law analysis of the protection of freedom of association in Latin American countries, taking into account the internal characteristic of associations and the horizontal efficacy of the right to association. It follows with an examination of the precedents by the Inter-American Court of Human Rights relating to right to association, concluding that such decisions, although not numerous, constitute a significant guideline for the protection of the right to association in the continent, where the true problem is the right's enforcement rather than its constitutional status.

KEYWORDS: Freedom of Association; Latin America; Fundamental Rights; Horizontal Efficacy.

SUMÁRIO: Introdução; 1. Conteúdo; 2. A organização interna das associações e os efeitos horizontais do direito à associação; 3. Regulação constitucional na América Latina; 4. Jurisprudência consultiva e contenciosa da Corte Interamericana de Direitos Humanos; Conclusão; Referências.

SUMMARY: Introduction; 1 . Content; 2 . The internal organization of associations and the horizontal effects of the right to association; 3. Constitutional regulation in Latin America; 4. Advisory and adjudicatory jurisprudence by the Inter-American Court of Human Rights; Conclusion, References.

SUMARIO: Introdución; 1. Contenido; 2. La organización interna de las asociaciones y los efectos horizontales del derecho de asociación; 3. Regulación constitucional en América Latina; 4. Jurisprudencia consultiva y contenciosa de la Corte Interamericana de Derechos Humanos; Conclusión; Referencias.

Artigo recebido em 5.06.2010. Artigo aceito para publicação mediante convite.

* Professor do Instituto de Investigações Jurídicas da Universidade Nacional Autônoma do México, Cidade do México. 


\section{INTRODUCCIÓN}

El derecho de asociarse libremente, o libertad de asociación, aparece en el artículo 16 de la Convención Americana de Derechos Humanos, cuyo texto es el siguiente:

1. Todas las personas tienen derecho a asociarse libremente con fines ideológicos, religiosos, políticos, económicos, laborales, sociales, culturales, deportivos o de cualquiera otra índole.

2. El ejercicio de tal derecho sólo puede estar sujeto a las restricciones previstas por la ley que sean necesarias en una sociedad democrática, en interés de la seguridad nacional, de la seguridad o del orden públicos, o para proteger la salud o la moral públicas o los derechos y libertades de los demás.

3. Lo dispuesto en este artículo no impide la imposición de restricciones legales, y aun la privación del ejercicio del derecho de asociación, a los miembros de las fuerzas armadas y de la policía.

En términos generales podemos afirmar que el derecho de asociación consiste en la libertad de todos los habitantes de una comunidad para conformar, por sí mismos o con otras personas, entidades que tengan una personalidad jurídica distinta de la de sus integrantes; es decir, se trata de poder constituir lo que Hans Kelsen llamaría un "centro de imputación de derechos y obligaciones", con el objeto y finalidad que sus integrantes libremente determinen, siempre que sea lícito.

La libertad de asociación tiene un papel esencial en la conformación de las democracias modernas, pues expresa la posibilidad de constituir agregados interpersonales de intereses, que tengan reconocida una personalidad jurídica. Por medio de las asociaciones las personas añaden un elemento importante a su convivencia y pueden expandir su horizonte vital, participando con otras personas en la consecución de ciertos fines. La participación asociativa incrementa el sentimiento cívico de los ciudadanos, les permite incidir de forma más directa en las decisiones importantes de su comunidad y refuerza los vínculos amistosos e incluso familiares. La participación asociativa es una de las formas más importantes de creación de lo que se ha denominado el "capital social”1.

Tiene razón Peter Häberle cuando escribe que la libertad de asociación es "un elemento irrenunciable de la democracia pluralista o de la Constitución del pluralismo", ; en el mismo sentido, pero muchos años antes, Alexis de Tocqueville escribía que "Después de la libertad de obrar solo, la más natural al hombre es la de combinar sus esfuerzos con los de sus semejantes y obrar en común. El derecho de asociación me parece casi tan inalienable por su naturaleza como la libertad individual. El legislador no puede querer destruirlo sin atacar a la sociedad misma”3.

\footnotetext{
${ }^{1}$ La caracterización sociológica del asociacionismo y su relación con el capital social puede verse en el importante libro de Putnam, Robert, Solo en la bolera. Colapso y resurgimiento de la comunidad norteamericana, Barcelona, Galaxia Gutemberg-Círculo de Lectores, 2002.

${ }^{2}$ Libertad, igualdad, fraternidad. 1789 como historia, actualidad y futuro del Estado constitucional, Madrid, Trotta, 1998, p. 79 (cursivas del autor).

${ }^{3}$ La democracia en América, México, FCE, 2007 (reimpresión), pp. 209-210.
} 
A veces se suelen analizar conjuntamente la libertad de asociación y la libertad de reunión. Normativamente puede resultar correcto, pero desde un punto de vista analítico, no deben confundirse ambos derechos.

La diferencia entre la libertad de reunión y la de asociación consiste sobre todo en la duración de los efectos que conlleva el ejercicio de una y otra. En tanto que la libertad de reunión despliega sus efectos mientras físicamente se encuentran reunidas las personas que la ejercen, la libertad de asociación se proyecta con efectos temporales más extendidos, en la medida en que se crea una personalidad jurídica distinta de la que corresponde a las personas que la ejercen.

\section{CONTENIDO}

Las libertades de reunión y asociación se encuentran reconocidas en muchas declaraciones internacionales de derechos humanos, como la Declaración Universal de 1948 (artículo 20), el Pacto de Derechos Civiles y Políticos (artículo 21), el Pacto de Derechos Económicos, Sociales y Culturales (artículo 8), la Convención Interamericana de Derechos Humanos (artículos 15 y 16) y el Convenio 87 de la Organización Internacional del Trabajo sobre libertad sindical.

A luz de dicha normativa, y sobre todo de la regulación constitucional de los mismos derechos, quizá sea oportuno distinguir entre el régimen jurídico de las asociaciones en general y el régimen jurídico de ciertas asociaciones en particular (que en ocasiones tienen un distinto marco de protección constitucional). El artículo 16 de la Convención Americana se refiere al derecho de asociación en general. Algunas normas constitucionales nacionales se refieren por ejemplo a asociaciones como los partidos políticos, las agrupaciones religiosas o los colegios profesionales. Esa regulación específica también contiene lo que llamamos derecho de asociación, pero con efectos y alcances distintos que la que rige para las asociaciones en general.

La libertad de asociación comporta la facultad del sujeto para ingresar a una asociación, pero también supone la posibilidad de salir de ella cuando lo considere oportuno; es decir, la libertad de asociación, para ser tal, nunca debe convertirse en algo obligatorio, ni para efecto del ingreso ni para efecto de la salida de una asociación (a menos que la obligación esté establecida directamente por el texto constitucional, como sucede con los colegios profesionales en España, aunque en este caso lo que es obligatorio es el ingreso, pero no la permanencia, puesto que dichos colegios pueden abandonarse en el momento que se quiera, con la consecuencia, sin embargo, de que ya no se podrá ejercer la actividad profesional que rigen los mismos colegios). La Declaración Universal de 1948 lo establece con meridiana claridad en su artículo 20.2: “Nadie puede ser obligado a pertenecer a una asociación”.

Las diferentes manifestaciones de la libertad de asociación quedan también muy bien reflejadas en el artículo 2 de la Ley Orgánica 1/2002 sobre derecho de asociación vigente en España; su contenido, en los párrafos que ahora interesan, establece que:

2. El derecho de asociación comprende la libertad de asociarse o crear asociaciones, sin necesidad de autorización previa.

3. Nadie puede ser obligado a constituir una asociación, a integrarse en ella o a

DIREITOS FUNDAMENTAIS E E JUSTIÇA N' 12 - JUL./SET. 2010 
permanecer en su seno, ni a declarar su pertenencia a una asociación legalmente constituida.

5. La organización interna y el funcionamiento de las asociaciones deben ser democráticos, con pleno respeto al pluralismo. Serán nulos de pleno derecho los pactos, disposiciones estatutarias y acuerdos que desconozcan cualquiera de los aspectos del derecho fundamental de asociación.

6. Las entidades públicas podrán ejercitar el derecho de asociación entre sí, o con particulares como medida de fomento y apoyo siempre que lo hagan en igualdad de condiciones con éstos, al objeto de evitar una posición de dominio en el funcionamiento de la asociación.

7. Las asociaciones que persiguen fines o utilicen medios tipificados como delito son ilegales.

La doctrina española ha llamado la atención sobre las dificultades que en la práctica pueden surgir al momento de intentar ponderar hasta dónde puede llegar la autonomía de las asociaciones frente al mandato de que su organización y funcionamiento interno sean democráticos ${ }^{4}$. Su Tribunal Constitucional ha señalado que

...La potestad de organización que comprende el derecho de asociación se extiende con toda evidencia a regular en los Estatutos las causas y procedimientos de la expulsión de los socios. La asociación tiene como fundamento la libre voluntad de los socios de unirse y permanecer unidos para cumplir los fines sociales, y quienes ingresan en ella se entiende que conocen y aceptan en bloque las normas estatutarias a las que quedan sometidos. $\mathrm{Y}$ en cuanto la asociación crea no sólo un vínculo jurídico entre los socios, sino también una solidaridad moral basada en la confianza recíproca y en la adhesión a los fines asociativos, no puede descartarse que los estatutos puedan establecer como causa de expulsión una conducta que la propia asociación, cuya voluntad se expresa por los Acuerdos de sus órganos rectores, valore como lesiva a los intereses sociales. Sentencia 218/1988.

Particularmente intensa puede ser esa tensión cuando la asociación de que se trata es un partido político. Al respecto el Tribunal Constitucional español ha señalado lo siguiente:

El precepto constitucional que consagra de modo genérico el principio de democracia interna admite muy diversas concreciones, ya que los modelos de organización partidista democrática que caben dentro del mencionado principio constitucional son muy diversos, tanto como dispares puede ser, en contenido $\mathrm{y}$ en intensidad, los derechos, y en general, el estatuto jurídico que puede atribuirse a los afiliados en orden a garantizar su participación democrática.... el legislador deberá respetar, además naturalmente del contenido esencial del derecho de participación democrática, el contenido de otros derechos como los que éste guarda íntima relación como son el derecho de libre creación y, muy

\footnotetext{
${ }^{4}$ González Pérez, Jesús y Fernández Farreres, Germán, Derecho de asociación. Comentarios a la Ley Orgánica 1/2002, de 22 de marzo, Madrid, Civitas, 2002, pp. 127 y ss.
} 
especialmente, el derecho de autoorganización del partido, un derecho, éste último, que tiende, precisamente, a preservar la existencia de un ámbito libre de interferencias de los poderes públicos en la organización y funcionamiento interno de los partidos. Sentencia 56/1995 .

En esa misma sentencia, el Tribunal entiende que la democracia interna exige "que los partidos rijan su organización y funcionamiento internos mediante reglas que permitan la participación de los afiliados en la gestión y control de los órganos de gobierno y, en suma... mediante el reconocimiento de unos derechos y atribuciones a los afiliados en orden a conseguir esa participación en la formación de la voluntad del partido”.

\section{LA ORGANIZACIÓN INTERNA DE LAS ASOCIACIONES Y LOS EFECTOS HORIZONTALES DEL DERECHO DE ASOCIACIÓN}

La intervención de los poderes públicos sobre las formas de organización interna de las asociaciones es uno de los puntos centrales de debate en torno a la libertad de asociación. No hay un modelo único de organización y, como principio general, debe prevalecer la más amplia libertad para quienes quieran conformar una asociación, a menos que se den algunas circunstancias excepcionales.

Por ejemplo, las asociaciones deben necesariamente tener un funcionamiento interno democrático cuando el ingreso en las mismas es un requisito para poder ejercer algún derecho fundamental; tal sería el caso, que ya se ha mencionado, de los partidos políticos, pero también estaríamos en el mismo supuesto tratándose de los colegios u organizaciones profesionales ${ }^{6}$, si es que la ley impone como requisito para ejercer determinada profesión la pertenencia a dichos órganos colegiados.

En los casos que se acaban de referir la libertad de organización interna cede en virtud de que se trata de instituciones que representan un interés no meramente particular, sino de carácter social y que llevan ese interés ante los órganos del poder público, lo que hace que requieran de un estatuto jurídico particular ${ }^{7}$.

También en ese supuesto se encuentran, al menos en algunos países, las federaciones deportivas que regulan alguna actividad deportiva profesional, así como las asociaciones que tienen por objeto la representación de algún interés social. En este último caso, se entiende que las asociaciones deben tener condiciones flexibles de ingreso, dado que "quien pretende asumir la condición de portavoz, ante las instancias públicas y en las relaciones sociales, de los intereses de un cierto colectivo de personas, debe permitir que confluyan a la formación de la voluntad del grupo todas las corrientes de opinión que se generen dentro del círculo de aquéllos a los que se dice querer representar”,

\footnotetext{
${ }^{5}$ Un análisis detallado de esta sentencia puede verse en Coderch, Pablo Salvador, Von Münch, Ingo y Ferrer, Josep, Asociaciones, derechos fundamentales y autonomía privada, Madrid, Civitas, 1997, pp. 74 y ss.

${ }^{6}$ Al respecto, ver artículo 36 in fine de la Constitución española. Sobre la posibilidad de que el requisito del funcionamiento democrático interno se pueda extender o no a todas las asociones, ver Elvira, Ascensión, “Asociaciones y democracia interna” en La democracia constitucional. Estudios en homenaje al profesor Francisco Rubio Llorente, Madrid, CEPC, UCM, Tribunal Constitucional, 2002, tomo I, pp. 607 y ss.

${ }^{7}$ Coderch, Pablo Salvador, Von Münch, Ingo y Ferrer, Josep, Asociaciones, derechos fundamentales y autonomía privada, cit., p. 21.

${ }^{8}$ Idem, p. 108.
} 
El derecho de asociación puede tener efectos, como es natural, frente a las autoridades, por ejemplo al limitar la posibilidad de que las mismas puedan disolver una asociación, de que le impongan decisiones tomadas por órganos externos o de que no le permitan a una persona formar parte de una organización, etcétera. Pero también puede, en determinadas circunstancias, tener efectos frente a particulares, es decir, dar lugar a la drittwirkung der grundrechte.

Hay dos circunstancias concretas en que los efectos horizontales de la libertad de asociación, pueden presentarse:

a) La primera se da cuando se incumplen los estatutos de la propia asociación; en este supuesto, uno o varios de sus miembros ven vulnerada su libertad de asociación. Dentro del alcance de dicha libertad se encuentra el hecho de que "quienes ingresan en una asociación, quienes lo pretenden y quienes desean permanecer en ella tienen derecho a que las reglas del juego en el que aceptan o aceptaron participar se cumplan hasta el final”;

b) La segunda se puede presentar cuando la asociación detenta una posición de monopolio dentro de una comunidad determinada ${ }^{10}$; en el ámbito del derecho de asociación el concepto de monopolio es difícil de delimitar y no puede transportarse mecánicamente desde la teoría económica, pero la idea que contiene es la de que si se trata de la única asociación que existe en una comunidad para realizar X o Y actividad, entonces la libertad de configuración de su organización interna debe ceder para asegurar un mínimo de condiciones; por ejemplo en cuanto a los requisitos de ingreso, los cuales no podrán ser discriminatorios.

Por lo que respecta a la posibilidad de utilizar algún criterio discriminatorio al momento de aceptar nuevos miembros dentro de una asociación, hay que decir que dicha posibilidad debe ser objeto de un escrutinio estricto por parte de los tribunales si se llega a presentar. A menos que se pruebe que existe un interés ineludible, que pone en riesgo la existencia misma de la asociación, no pueden esgrimirse criterios discriminatorios para impedir el ingreso de alguna persona en una asociación.

Este segundo caso se presenta, por mencionar dos ejemplos, cuando se trata del único club deportivo que tiene una pileta de natación en la comunidad, o si se trata de la única academia en la que se puede obtener la licencia para ser piloto aviador. En estos casos no se podría prohibir por medio de disposiciones estatutarias internas el ingreso a las mujeres, por citar un caso que ha tenido que ser decidido por algunos tribunales constitucionales. El mismo razonamiento se ha aplicado a los llamados "clubs privados” en los Estados Unidos, que solamente admitían como socios a hombres ${ }^{11}$.

${ }^{9}$ Coderch, “Introducción” en Coderch, Pablo Salvador, Von Münch, Ingo y Ferrer, Josep, Asociaciones, derechos fundamentales y autonomía privada, cit., p. 18.

${ }^{10}$ Idem, pp. 18 y 103 y ss.

${ }^{11}$ A partir de importantes sentencias de la Suprema Corte, como por ejemplo en la sentencia del caso New York State Club Association vs. City of New York, resuelto por unanimidad de votos en junio de 1988, siguiendo el criterio ya establecido en la sentencia Roberts vs. U.S. Jaycees fallado en 1984. El criterio de la Corte se aplica a las asociaciones que no sean "estrictamente privadas" (es decir, las que no ofrezcan servicios al público); no se aplica, sin embargo, a las corporaciones religiosas. 
En algunos casos particulares, se ha admitido que también están sujetas a los mismos límites las asociaciones que, sin ser monopólicas, tengan una posición dominante dentro de un ámbito social o económico determinado ${ }^{12}$.

\section{REGULACIÓN CONSTITUCIONAL EN AMÉRICA LATINA}

Las Constituciones de América Latina contienen una regulación en general adecuada de la libertad de asociación. Llama la atención el grado de detalle de algunos textos y, sobre todo, la forma de enunciar los límites al derecho (se trata de una cuestión llamativa en el caso de todos los derechos, no solamente respecto de la libertad de asociación).

La enunciación regulativa en las constituciones de la región va desde el escueto mandato del texto argentino "Todos los habitantes de la Nación gozan de los siguientes derechos....: de asociarse con fines útiles” (artículo 14), colombiano "Se garantiza el derecho de libre asociación para el desarrollo de las distintas actividades que las personas realizan en sociedad” (artículo 38), o boliviano (tan amplio en muchas otras cosas), "Las bolivianas y los bolivianos tienen los siguientes derechos: 4. A la libertad de reunión y asociación, en forma pública y privada, con fines lícitos” (artículo 21), hasta las regulaciones más amplias de la Constitución brasileña (artículo 5 fracciones XVII, XVIII, XIX, XX y XXI), nicaragüense (artículo 49), venelozana (artículos 52, 67 y 118) o mexicana (artículos 9, 41 y 130).

Si revisamos la regulación constitucional que acabamos de citar (y las otras pertinentes), veremos que la libertad asociativa se limita por sus objetivos (licitud de los fines) y por razones incluso más etéreas y difíciles de definir. Por ejemplo, en Chile se prohíben las asociaciones contrarias a "la moral” (artículo 19). En Honduras la libertad de asociación debe ser compatible con "las buenas costumbres" (artículo 78). La licitud aparece en varios textos constitucionales (en el mexicano, por ejemplo: artículo 9). Lo que signifiquen ese tipo de conceptos tan vagos e indeterminados es algo que habrá que ir descifrando, pero cabe apuntar que no resulta un modelo de buena técnica legislativa y más bien abren la puerta para interpretaciones subjetivas.

En algún país hay menciones específicas respecto de la restricción para las fuerzas armadas y la policía. Es el caso al menos de Colombia (artículo 39).

La Convención Americana, en su artículo 16, no se libra de una enunciación ciertamente amplia de los límites, pues agrega en su párrafo segundo la posibilidad de considerar cuestiones vinculadas con la seguridad nacional, la seguridad pública, el orden público, la moral pública o los derechos de los demás, para efecto de configurar el perímetro jurídicamente protegido de la libertad asociativa.

La ventaja que se tiene en el sistema interamericano es que la Corte Interamericana de Derechos Humanos ha hecho siempre una interpretación del todo pertinente y acotada de los límites a los derechos, a través de la clave hermenéutica que proporciona el concepto de "sociedad democrática"”. No podemos decir lo mismo

\footnotetext{
${ }^{12}$ Coderch, “Introducción”, cit., p. 105.

${ }^{13}$ Las restricciones a los derechos deben ser congruentes y compatibles con las necesidades de una sociedad democrática, tal como se enuncia en varias sentencias de la Corte e incluso en la propia Convención Americana.
} 
de las jurisdicciones constitucionales internas, que a veces utilizan conceptos vagos para restringir indebidamente derechos, incluyendo el derecho de asociación.

4. JURISPRUDENCIA CONSULTIVA Y CONTENCIOSA DE LA CORTE INTERAMERICANA DE DERECHOS HUMANOS

La Corte Interamericana de Derechos Humanos ha hecho, a lo largo de su historia, varias referencias puntuales a la libertad de asociación y sus alcances. Lo ha hecho en la Opinión Consultiva 5/85 sobre colegiación obligatoria de periodistas y en los casos contenciosos Huilca Tecse vs. Perú (3 de marzo de 2005), Cantoral Huamaní y García Santa Cruz vs. Perú (10 de julio de 2007) y Escher y otros vs. Brasil (6 de julio de 2009). Veamos algunas de las consideraciones más importantes que aporta la Corte respecto del derecho de libertad de asociación que estamos analizando.

\section{A) Opinión Consultiva 5/85}

En la OC 5/85, se consultaba a la Corte sobre el apego a la Convención Americana de una disposición legislativa de Costa Rica, por medio de la cual se exigía la colegiación obligatoria para aquellas personas que quisieran ejercer la profesión periodística, incluyendo la función de reportero.

La Corte comienza su análisis, como no podría ser de otra manera, a partir de la libertad de expresión y su papel en todo Estado democrático (los párrafos 30 a 34, 39, 70 y 71, son especialmente importantes en el orden de lo conceptual). También se refiere la Corte a las restricciones de la libertad de expresión, aplicables en alguna medida a la libertad de asociación; en efecto, la Corte construye en la OC 5/85 un concepto de “orden público” (párrafo 64) y de "bien común” (párrafos 65 y 66).

La Corte estima que las personas que deseen ejercer el periodismo no pueden ser obligadas a integrarse en un colegio profesional, dado el importante lugar que tienen la libertad de expresión y el pluralismo mediático en una sociedad democrática: "la libertad de expresión se inserta en el orden público primario y radical de la democracia, que no es concebible sin el debate libre y sin que la disidencia tenga pleno derecho de manifestarse” (párrafo 69); "una sociedad que no está bien informada no es plenamente libre” (párrafo 70).

El periodismo no se concibe como una profesión más, por su íntimo vínculo con la libertad de expresión (párrafo 71). Para la Corte, el periodismo disfruta de una garantía de mayor libertad que otras profesiones, a la luz de lo que dispone la Convención Americana de Derechos Humanos en su artículo 13 (libertad de expresión). Expresamente, la Corte distingue al periodismo de profesiones como el derecho o la medicina, que no son actividades profesionales específicamente garantizadas (en lo relativo a su ejercicio) por la Convención Americana.

La colegiación obligatoria, entiende la Corte, atenta contra la necesaria libertad e independencia que deben tener los periodistas, las cuales deben ser protegidas y garantizadas (párrafos 78 y 79).

La OC 5/85 viene acompañada de algunas opiniones separadas. La del juez Rafael Nieto Navia se refiere con un énfasis especial a la libertad de asociación 
(párrafos 6 y 8 de su voto). Argumenta en el sentido de que el carácter de asociados se debe adquirir, como regla general, de forma voluntaria, no compulsiva, para que pueda ser compatible con el artículo 16 de la Convención Americana. El juez Máximo Cisneros destaca en su "Declaración" que acompaña a la OC 5/85, la importancia de los colegios profesionales de periodistas, considerando que su mera existencia no es incompatible con la Convención, siempre que los requisitos para colegiarse sean razonables. Es decir, abona en el sentido de que la legislación costarricense debe adecuarse a lo dispuesto por el sistema interamericano, pero pudiendo eventualmente mantener los colegios de periodistas, bajo reglas distintas a las que en ese entonces estaban vigentes y fueron objeto de la consulta del Estado-parte. En un sentido parecido se expresa el juez Pedro Nikken en su propia “Declaración” (párrafo 7).

\section{B) Huilca Tecse vs. Perú}

El caso Huilca Tecse trata sobre violaciones muy graves de derechos humanos. La libertad de asociación no es la peor de ellas, pero lo importante para nuestro objeto de estudio es que la Corte Interamericana hace un análisis interesante de sus alcances, por vez primera en un caso contencioso. Los representantes de la víctima aducen expresamente la violación del artículo 16 de la Convención Americana y el Estado-parte reconoce su responsabilidad por ella (párrafos 19 y 20 de la sentencia).

El señor Huilca Tecse fue privado de la vida. La investigación fue totalmente deficiente. La Corte analiza con detalle la violación del derecho a la vida. Para el análisis de la libertad de asociación lo relevante es que Huilca era un destacado dirigente sindical. Su militancia gremial fue, con toda probabilidad, la causa para que se atentara contra su vida (párrafo 68 de la sentencia).

La afectación, bajo esas circunstancias, se produce no solamente respecto de la víctima directa, sino de todas las demás personas que participan en la asociación, ya que se ven amedrentadas o inhibidas en el ejercicio de ese derecho fundamental. La libertad de asociarse debe ser ejercida sin miedo o temor, dice la Corte (párrafo 69), abriendo de esa forma una veta jurisprudencial que retomará en posteriores pronunciamientos.

La libertad de asociación tiene dos dimensiones. Una individual que, en materia laboral, se corresponde con la posibilidad de formar sindicatos y utilizar cualquier medio que se apropiado para ejercer dicha libertad (párrafo 70). Los medios para su ejercicio deben ser reales y efectivos, sin que se puedan reducir de tal manera que se conviertan en algo ilusorio o meramente formal. Si el Estado no garantiza que las personas se integren en sindicatos libremente, se disminuye la capacidad de tales organizaciones para funcionar como elementos de protección de sus intereses legítimos (ver párrafo 77).

La dimensión social de la libertad de asociación "es un medio que permite a los integrantes de un grupo o colectividad laboral alcanzar determinados fines en conjunto y beneficiarse de los mismos" (párrafo 71). La muerte de Huilca Tecse no solamente produjo el efecto, ciertamente grave, de privarlo de la vida, sino que además disminuyó la libertad asociativa de un grupo social, por efecto del amedrentamiento (párrafo 78).

DIREITOS FundAMENTAIS E E JUSTIÇA N' 12 - JUL./SET. 2010 
La Corte ordena, en el capítulo de reparaciones de la sentencia, distintas medidas que pueden tener un efecto positivo sobre la libertad de asociación. Tal es el caso, desde nuestro punto de vista, del establecimiento de una cátedra o cursos de derechos humanos que lleve el nombre de la víctima (párrafo 113), la de exaltar y recordar su labor en la celebración oficial del 1 de mayo (párrafo 114), o la de construir un busto en su memoria (párrafo 115).

\section{C) Cantoral Huamaní y García Santa Cruz vs. Perú}

El caso Cantoral Huamaní guarda ciertas similitudes con el caso Huilca Tecse que se acaba de analizar brevemente. En ambos casos el Estado que termina siendo condenado es Perú, en ambos casos se presenta un homicidio de personas, en ambos casos las víctimas formaban parte de asociaciones representativas de trabajadores y en ambos casos la Corte Interamericana se refiere a la violación del derecho de asociación por virtud del efecto inhibitorio que sobre su ejercicio tiene la violación de otros derechos.

Saúl Cantoral Huamaní y Consuelo Trinidad Santa Cruz eran destacados integrantes de asociaciones de mineros. El primero era un importante líder sindical, que impulsó y dirigió huelgas en ese sector de la economía; fue objeto de permanentes amenazas y varios secuestros. La segunda era fundadora de una asociación social dedicada a capacitar y a asesorar a amas de casa en los campamentos mineros peruanos (párrafos 142 y 143 de la sentencia).

La Corte cita en la sentencia de Cantoral Huamaní el caso Huilca Tecse para recordar que la libertad de asociación no solamente supone obligaciones negativas para los Estados parte de la Convención Americana (es decir, omisiones), sino que también comporta "obligaciones positivas de prevenir los atentados contra la misma, proteger a quienes la ejercen e investigar las violaciones de dicha libertad. Estaso obligaciones positivas deben adoptarse, incluso en la esfera de relaciones entre particulares, si el caso lo amerita” (párrafo 144).

Nos recuerda que el Comité de Libertad Sindical de la OIT ha señalado que los derechos sindicales no pueden ejercerse en un contexto de impunidad frente a situaciones de violencia en contra de las organizaciones gremiales o de sus líderes, las cuales pueden comportar -por ejemplo- ejecuciones extrajudiciales (párrafo 145).

La sentencia señala con contundencia la obligación del Estado peruano (y de todo Estado parte de la Convención, claro está) de investigar con la debida diligencia y de forma efectiva los delitos en contra de dirigentes sindicales, pues de otra manera se genera un efecto inhibitorio muy importante sobre el derecho de asociación. La diligencia citada debe ser acentuada, señala la Corte, en contextos en los que existe violencia contra los sindicatos (párrafos 146).

El efecto inhibitorio no se limita a las víctimas directas e indirectas, sino a cualquier persona que quiera formar parte de una asociación minera, pero que va a sentir miedo o temor a sufrir represalias; el efecto intimidante, señala la Corte, "se acentúa y hace mucho más grave por el contexto de impunidad que rodea al caso” (párrafo 148). 


\section{D) Caso Escher y otros vs. Brasil}

Este caso es distinto a los anteriores debido a que las violaciones a los derechos de las víctimas son relativamente menos graves. $\mathrm{N}$ se trata de ejecuciones y desapariciones forzadas, sino de una vulneración a las comunicaciones privadas de personas que formaban parte de una asociación y su posterior difusión a través de los medios masivos de comunación.

Tales intromisiones, señala la Corte, alteran y desnaturalizan el derecho de asociación, al constituirse como una injerencia indebida por parte de las autoridades (párrafo 170).

Además, la Corte reitera el alcance de las obligaciones positivas a cargo del Estado, a efecto de prevenir atentados contra el derecho de asociación, proteger a quienes la ejercen e investigar sus eventuales violaciones; tales obligaciones se proyectan no solamente a las relaciones entre las autoridades y los particulares, sino también a las relaciones entre particulares únicamente (párrafo 171).

La interceptación de comunicaciones privadas y su posterior difusión a través de los medios de comunicación masiva generaron temor intenso en las víctimas (según su propio dicho) y crearon problemas entre las personas que participaban de las asociaciones en cuestión, además de que afectaron a la imagen de dichas organizaciones (párrafo 180).

La sentencia se acompaña con un importante voto concurrente del juez Sergio garcía Ramírez, quien abunda sobre el contenido del derecho a la intimidad y su conculcación por parte de las autoridades que realizaron las intervenciones telefónicas (ver por ejemplo párrafos 2, 3, 4 y 7 de su voto).

\section{CONCLUSIÓN}

Si bien con distintos matices y a veces señalando límites injustificados, lo cierto es que las Constituciones de América Latina protegen el derecho a asociarse libremente, tanto en general como respecto de asociaciones en particular (consumidores, partidos políticos, agrupaciones religiosas, etcétera). Podemos decir que, aunque siempre serán mejorables, contamos con esquemas constitucionales que permiten una tutela efectiva de dicho derecho, conforme a los márgenes aceptados por los Estados democráticos de nuestros días.

Ahora bien, el problema no está en el régimen constitucional del derecho de asociación, sino en la práctica del mismo. Y así si, las cuestiones pendientes son de una dimensión preocupante.

Como se pudo comentar, el tema ha sido objeto de distintos pronunciamientos por parte de la Corte Interamericana de Derechos Humanos.

La opinión consultiva 5/85 y las sentencias que la Corte ha dedicado al derecho de asociación no conforman un corpus jurisprudencial tan extenso y detallado como el que existe en otros temas, pero reflejan con claridad la problemática de orden más general que presentan los derechos fundamentales en la región. Me refiero a los problemas de desapariciones forzadas, ejecuciones extrajudiciales, faltan de investigación profesional 
del delito, impunidad generalizada, violaciones a la intimidad, represión de movimientos obreros y un largo etcétera.

Es en ese contexto, bien diferente de aquel en el que ha desenvuelto su jurisprudencia el Tribunal Europeo de Derechos Humanos ${ }^{14}$, que la Corte ha ido asentando algunos principios de la mayor relevancia sobre la libertad asociativa, los cuales con toda seguridad servirán de parámetro jurisprudencial para casos que en lo futuro se llegasen a presentar en torno a la misma temática.

\section{REFERENCIAS}

BILBAO UBILLOS, Juan María. "Las libertades de reunión y asociación: algunas vacilaciones en una trayectoria de firme protección (art. 11 CEDH)”. In: GSRCÍA ROCA, Javier; SANTOLAYA, Pablo (Coords.). La Europa de los derechos. El Convenio Europeo de Derechos Humanos, $2^{a}$ edición, Madrid, CEPC, 2009.

CODERCH, Pablo Salvador; VON MÜNCH, Ingo; FERRER, Josep. Asociaciones, derechos fundamentales y autonomía privada. Madrid, Civitas, 1997.

ELVIRA, Ascensión, “Asociaciones y democracia interna” In: La democracia constitucional. Estudios en homenaje al profesor Francisco Rubio Llorente, Madrid, CEPC, UCM, Tribunal Constitucional, 2002, tomo I.

GONZÁLEZ PÉREZ, Jesús; FERNÁNDEZ FARRERES, Germán. Derecho de asociación. Comentarios a la Ley Orgánica 1/2002, de 22 de marzo, Madrid, Civitas, 2002.

HÄBERLE, Peter. Libertad, igualdad, fraternidad. 1789 como historia, actualidad y futuro del Estado constitucional, Madrid, Trotta, 1998.

PUTNAM, Robert. Solo en la bolera. Colapso y resurgimiento de la comunidad norteamericana, Barcelona, Galaxia Gutemberg-Círculo de Lectores, 2002.

TOCQUEVILLE, Alexis de. La democracia en América, México, FCE, 2007.

\footnotetext{
${ }^{14}$ Bilbao Ubillos, Juan María, "Las libertades de reunión y asociación: algunas vacilaciones en una trayectoria de firme protección (art. 11 CEDH)” en García Roca, Javier y Santolaya, Pablo (coordinadores), La Europa de los derechos. El Convenio Europeo de Derechos Humanos, $2^{\mathrm{a}}$ edición, Madrid, CEPC, 2009, pp. 629 y siguientes.
} 